\title{
Elimination of ESD Events and Optimizing Waterjet Deflash Process for Reduction of Leakage Current Failures on QFN-mr Leadframe Devices
}

\author{
Frederick Ray I. Gomez and Tito T. Mangaoang Jr. \\ Back-End Manufacturing \& Technology, STMicroelectronics, Inc., Calamba City, Laguna 4027, Philippines
}

\begin{abstract}
This technical paper presents the resolution of high leakage current failures on QFN-mr (Quad-Flat No-leads Multi-Row) LF (leadframe) devices by optimizing the waterjet deflash process and eliminating the ESD (electrostatic discharge) events. ESD damage to units can cause permanent or latent product failures which results in low final test yield, and worse, possible external customer complaints. The use of $\mathrm{CO}_{2}$ (carbon dioxide) bubbler was able to reduce the DI (deionized) water's equivalent resistivity from $17 \mathrm{M} \Omega$ to $0.30 \mathrm{M} \Omega$, minimizing the tribocharging effect produced during the waterjet deflash process. Moreover, ESD events were eliminated by grounding the floating assembly equipment parts and installing appropriate ESD controls. It is of high importance to reduce or eliminate the leakage current failures to ensure the product quality, especially as the market becomes more demanding. After the optimization and implementation of the corrective and improvement actions, high leakage current occurrence was significantly reduced from baseline of $5,784 \mathrm{ppm}$ to $20 \mathrm{ppm}$.
\end{abstract}

Key words: Leakage current failure, ESD, QFN-mr LF, waterjet deflash process.

\section{Introduction}

STMicroelectronics offers great range of packages for a very wide portfolio of applications, one of which is the QFN-mr (Quad-Flat No-leads Multi-Row) LF (leadframe) device being used on hard disk drives as motor controllers. It is designed with $\mathrm{BCD} 8$ (Advanced Bipolar-CMOS-DMOS) technology and packaged on QFN-mr platform utilizing a tapeless LF technology. As the die technology becomes smaller, faster, and thinner, circuit metallization also becomes smaller, thus the device or package in general becomes more sensitive and susceptible to ESD (electrostatic discharge) damage. Discussion on the fundamentals of ESD and ESD damage could be found in the ESD Association references [1]. Presence of static charges, speed of material separation, improper grounding, and triboelectric charging (or simply tribocharging) could cause ESD damage to

Corresponding author: Frederick Ray I. Gomez, M.S., research fields: package electrical modeling and simulation.
ESD-sensitive device. As the market cycle time becomes more demanding, there is a need to address package related issues at the soonest as possible.

Tapeless LF has an additional backetch process to form the lead footprint and waterjet deflash process to remove the metal burrs (specifically copper burrs) induced by the etching process. During waterjet process, high speed and highly pressurized DI water is being applied to the units. A visual comparison of the LF at these processes is illustrated in Fig. 1. This high waterjet pressure creates high triboelectric charging (or simply tribocharging) and could cause ESD damage to the units.

\subsection{Device Defect in Focus}

PPAT (parametric parts average testing) on leakage current response was employed at final test to screen-out or reject units that are outliers (above 5-sigma) from a reference distribution. Fig. 2 shows the outliers on 1 lot of Device A. The reference distribution is obtained on the response of the first 50 units tested. 
Most of the rejections do not manifest any abnormality after FA (failure analysis) since the leakage current readings are still within the defined specification limits. However, the units are considered failing since they are outliers from the PPAT testing. For units above the specification limits, FA showed burnt metallization as shown below. This defect manifestation could be brought by an EOS (electrical overstress)/ESD issue, as depicted in Fig. 3.

It is imperative to reduce the leakage current failures to ensure the product quality. If the leaky unit/device is functioning, leaky connection will eventually degrade and become open-circuit, ultimately disable the functionality of the device.

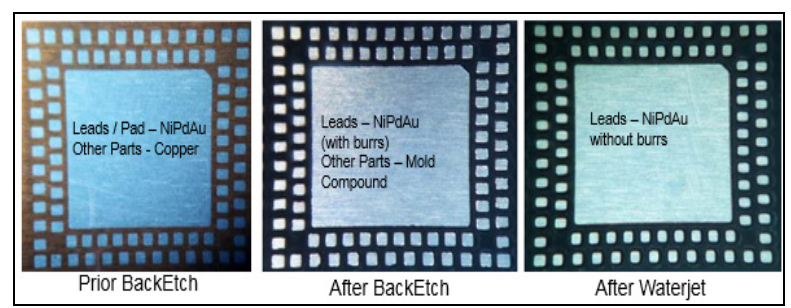

Fig. 1 Tapeless LF bottom side visual comparison.

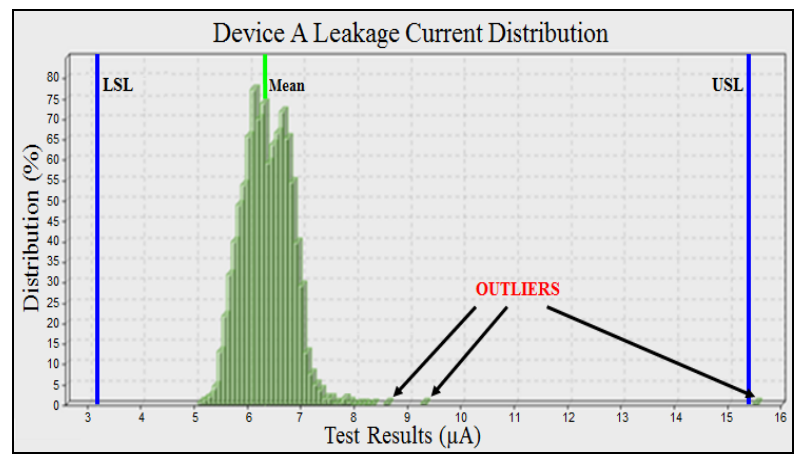

Fig. 2 Leakage current PPAT response, showing outliers.

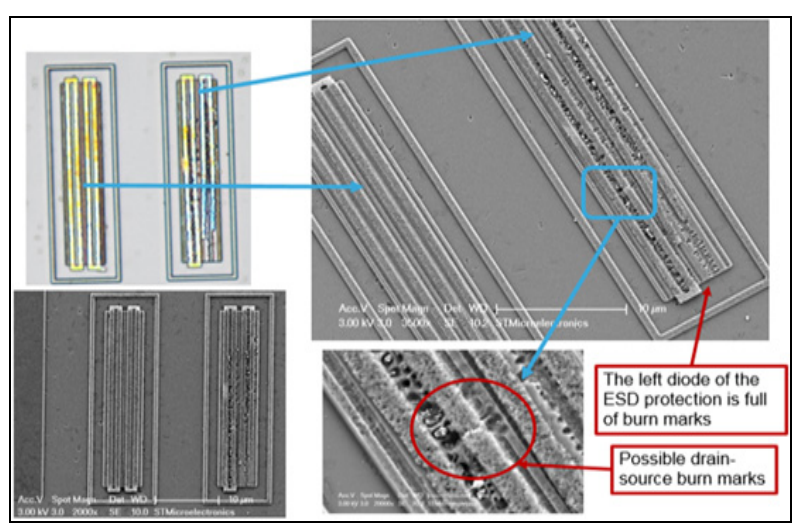

Fig. 3 EOS/ESD defect manifestation.
1.2 Leakage Current Defect Ppm Baseline and Six Sigma Goal

With a baseline of 5,784 ppm and an entitlement of 4,257 ppm, the calculated Six Sigma Goal is at 4,715 ppm (70\% improvement), as illustrated in Fig. 4.

The lots processed for the workweek 1620-26 showed that most of the defectives lie on $0.57 \%$ and the long term sigma (current process capability) was calculated at 2.5309, see Fig. 5 .

\subsection{Objective Statement}

Based on the earlier calculations, the objective of the paper is to eventually reduce the leakage current rejections from 5,784 average ppm to $4,715 \mathrm{ppm}$ or even lower. As previously stated, It is of high importance to reduce and/or eliminate the occurrence of leakage current failures to ensure the product quality. Leaky units will eventually degrade and affect the performance for the application.

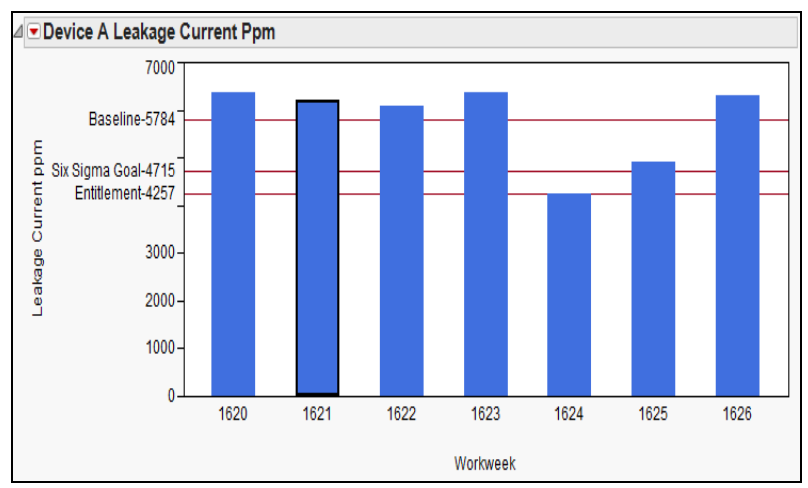

Fig. 4 Baseline and six sigma goal.

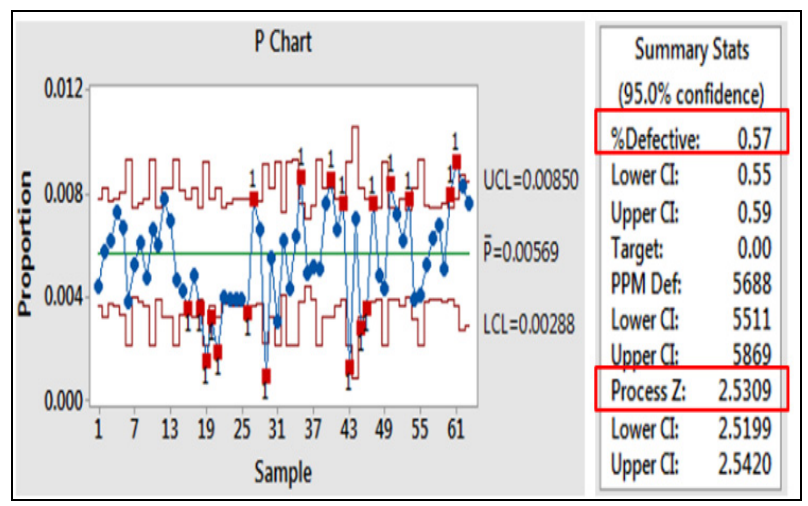

Fig. 5 Current process capability. 


\section{Review of Related Literature}

Based on literature studies, some possible causes of high leakage current rejections and damage or burnt metallization related to assembly manufacturing include electrostatic damage to sensitive devices, tribocharging effects due to high waterjet parameters, and high water resistivity during high-pressure cleaning. ESD damage to units can be explained by three models [1] as shown in Fig. 6.

The effect of high tribocharging brought by waterjet deflash was also studied by Llana et al. [2]. Lower waterjet pressure and temperature resulted to lower supply current failures. Some of the failures were also recovered after subjecting the units to baking or removal of package moisture content.

Wafer saw process can also contribute to the unit's susceptibility to ESD damage, see Fig. 7. Processing without $\mathrm{CO}_{2}$ bubbler or injector and ionizer showed higher discharge voltage at $18.6 \mathrm{kV}$ as compared to a wafer saw process with the installed equipment [3].

Another study [4] showed that plasma process with high cleaning parameters resulted to damage gate oxide, as illustrated in Fig. 8.

At mold station, leakage current was also experienced on some molding compounds due to thermally induced/trapped charge failure mechanism [5]. Some molding compounds also tend to have carbon agglomeration, forming a conductive path thus shorting adjacent pins [6].

\section{Methodology}

An ESD event mapping was carried out to determine the scope of the ESD event measurement and assessment. All process steps and equipment were investigated since all of these steps could induce ESD damage to the units (possible failure mechanism).

A handheld ESD event meter in Fig. 9 was used in all process stations to measure any ESD event with voltage setting at $>1 \mathrm{kV}$. Some limitations on the measurement were encountered during curing process, molding, and the waterjet deflash process. The equipment at these processes could not be opened while in active/working mode, hence limiting the placement or location of the ESD event meter during measurement.

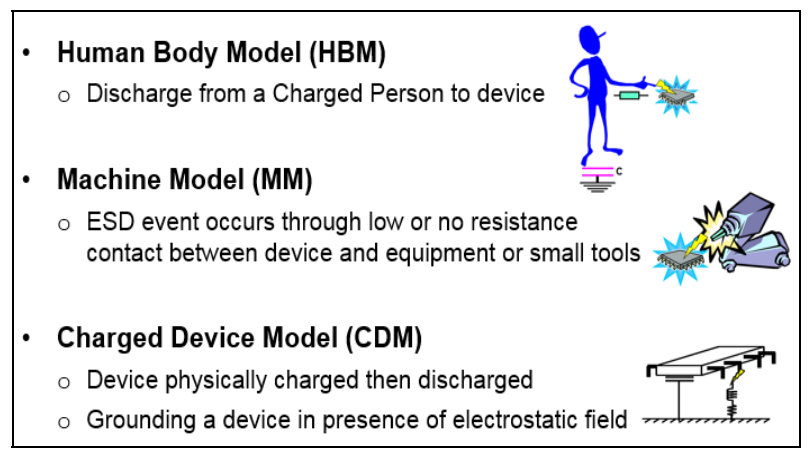

Fig. 6 ESD models [1].

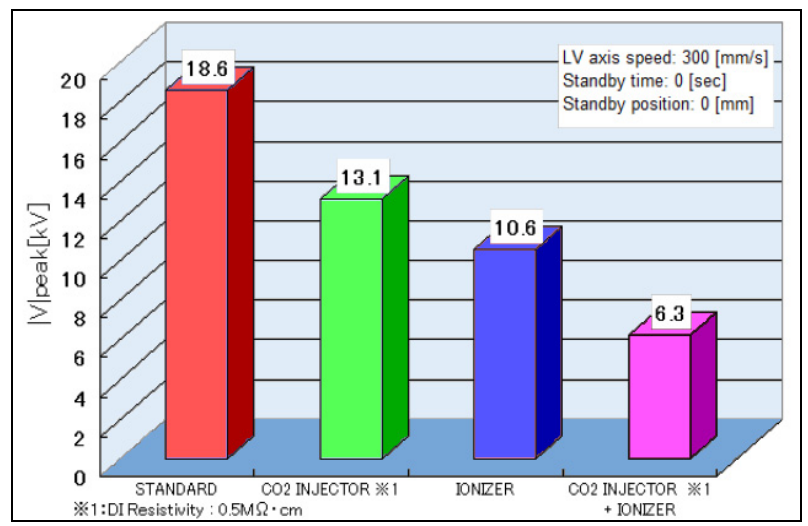

Fig. 7 Discharge voltage at wafer saw [3].

Physical analysis of the device fail which was etch to layer showed damage gate oxide structure resulting to leaky MOS.
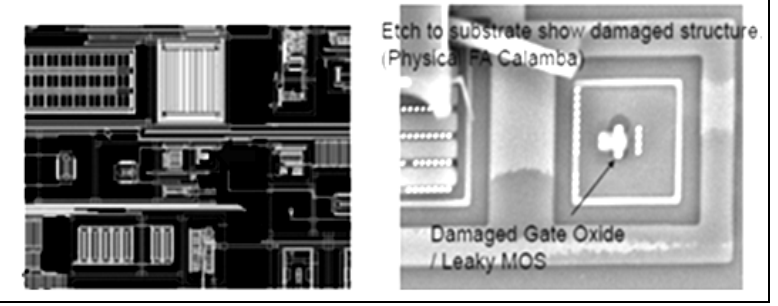

Fig. 8 Damage gate oxide with plasma process.

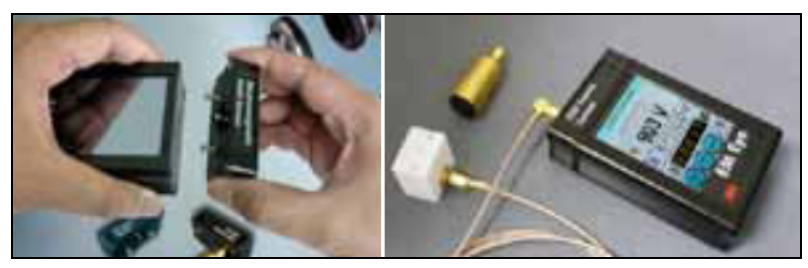

Fig. 9 Handheld ESD event meter by $3 M^{\mathrm{TM}}$. 


\section{Results and Analysis}

Assessment on the ESD event mapping is shown in Table 1. Investigation showed that there were ESD events on Diebonder A, causing higher leakage current occurrence.

The equipment was then subjected to health check and the ESD events were zeroed out by grounding the machine floating parts. The assessment and the corrective actions were considered quick wins, causing the leakage current occurrence significantly reduced from 5,784 ppm average to $1,567 \mathrm{ppm}$ average for workweek 1627-29.

After implementation of the corrective and improvement actions, leakage current occurrence greatly reduced from a baseline of $5,784 \mathrm{ppm}$ to average of 1,567 ppm last workweek 1627-29, see Fig. 10. This is significantly better than the target performance at $4,715 \mathrm{ppm}$.

\subsection{Tribocharging Effects}

As earlier mentioned, tribocharging is a source of ESD. Factors like high rubbing speed, higher pressure, lower relative humidity, and higher temperature usually result in higher charge build-up. Shown in Table 2 is the evaluation on possible tribocharging effects in the assembly process.

Waterjet process with varying DI water resistivity levels (high - $17 \mathrm{M} \Omega$, low - $0.3 \mathrm{M} \Omega$ ) shows significant result, with $p$-value $<0.05$ ( $p$-value $=0$ to be exact, see Fig. 11), thus considered critical. This zero leakage current PPAT was obtained for waterjet deflash process with installed $\mathrm{CO}_{2}$ bubbler.

An illustration for tribocharging at waterjet station and the setup for $\mathrm{CO}_{2}$ bubbler are shown in Fig. 12 and Fig. 13, respectively.

The $\mathrm{CO}_{2}$ bubbler has a resistivity setting ranging from $0.2 \mathrm{M} \Omega$ to $0.4 \mathrm{M} \Omega$. This range value is still within the static dissipative range. A static dissipative material allows slow dissipation or attenuation of charge from a charged device. The rate of discharge is slow and controlled such that no damage is done to an ESD sensitive device. The equivalent model representation is shown in Fig. 14. With the addition of $\mathrm{CO}_{2}$ bubbler to lower the resistivity (and resistance) of DI water, the equivalent resistance of the discharge path becomes $R$ eq $=R_{\mathrm{DI}} / / R_{\mathrm{CO}_{2}}$.

With lower Req, but still within the static dissipative range, higher current $I$ could flow to the

Table 1 ESD event mapping assessment.

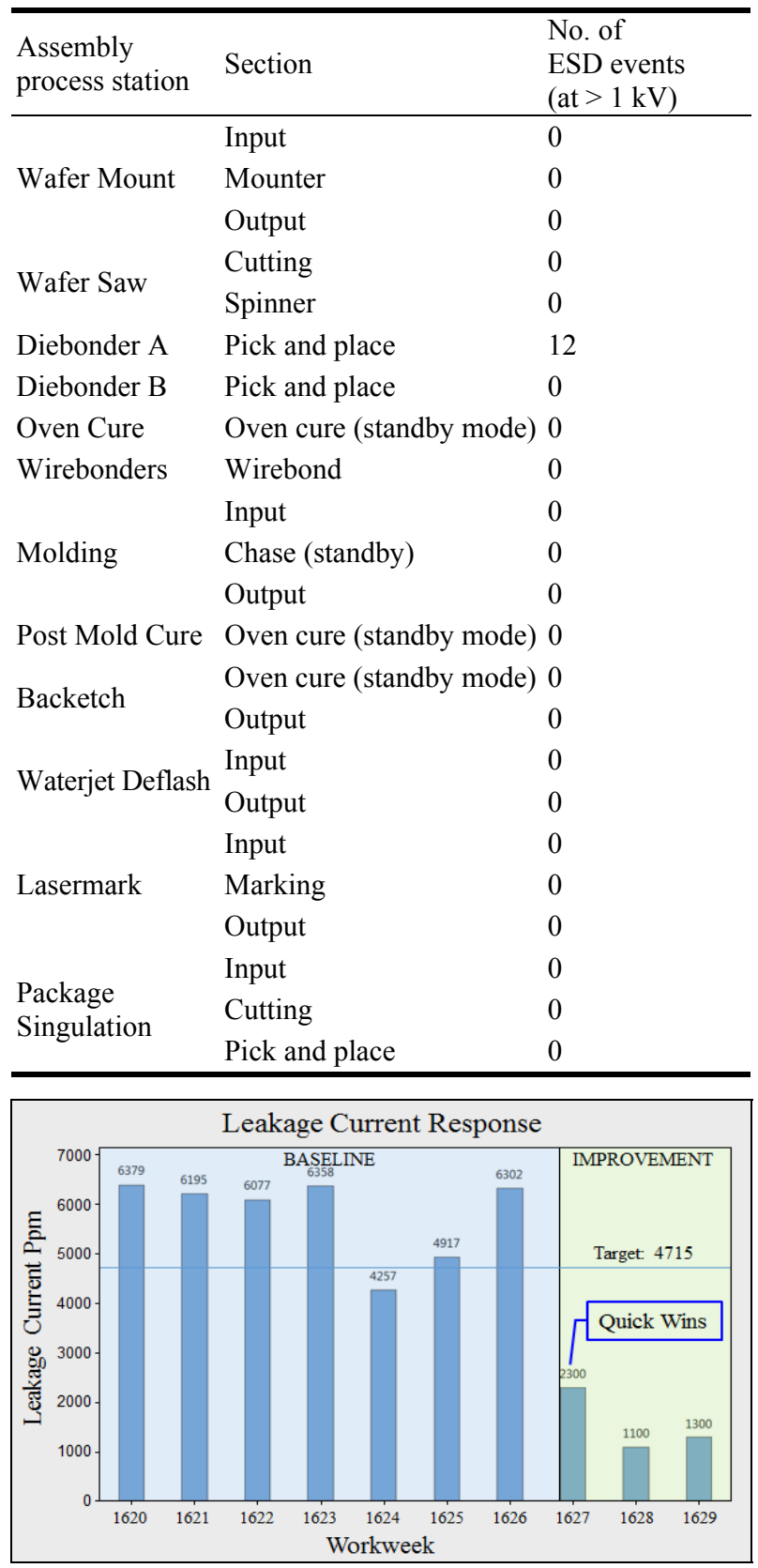

Fig. 10 Leakage current ppm improvement. 
Table 2 Evaluation on tribocharging effects.

\begin{tabular}{|c|c|c|c|c|c|c|c|c|}
\hline Y & $\begin{array}{l}\text { Unit of } \\
\text { measure }\end{array}$ & $\begin{array}{l}Y \text { treated } \\
\text { as }\end{array}$ & $\mathrm{X}$ & $\begin{array}{l}\text { True nature } \\
\text { of } X\end{array}$ & Levels of $X$ & $p$-value & Decision & $\begin{array}{l}\text { Potential failure } \\
\text { mechanism }\end{array}$ \\
\hline \multirow{4}{*}{$\begin{array}{l}\text { Leakage } \\
\text { Current }\end{array}$} & \multirow{4}{*}{ ppm } & Discrete & $\begin{array}{l}\text { Wafer saw transfer } \\
\text { arm speed }\end{array}$ & Discrete & Low, high & 0.282 & $\mathrm{X}$ is not significant & \multirow{4}{*}{ ESD Damage } \\
\hline & & Discrete & $\begin{array}{l}\text { Wafer saw } \\
\text { atomizing pressure }\end{array}$ & Discrete & Low, high & 0.058 & $\mathrm{X}$ is not significant & \\
\hline & & Discrete & $\begin{array}{l}\text { Wirebond machine } \\
1 \text { ionizer }\end{array}$ & Discrete & $\begin{array}{l}\text { Good, } \\
\text { defective }\end{array}$ & 0.298 & $\mathrm{X}$ is not significant & \\
\hline & & Discrete & $\begin{array}{l}\text { Waterjet water } \\
\text { resistivity }\end{array}$ & Discrete & Low, high & 0 & $\begin{array}{l}\mathrm{X} \text { is significant, } \\
\text { hence, moves } \\
\text { forward }\end{array}$ & \\
\hline
\end{tabular}

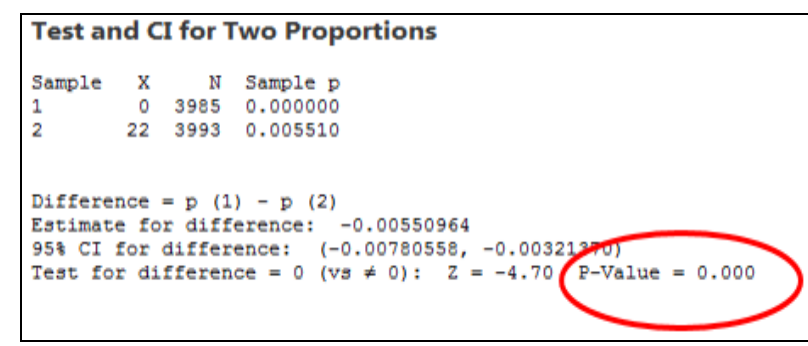

Fig. 11 Proportion test on water resistivity levels.

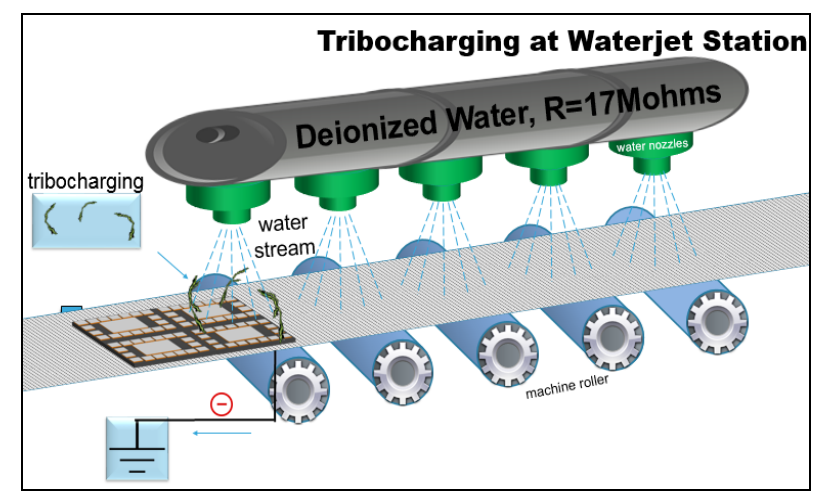

Fig. 12 Tribocharging at waterjet deflash process.

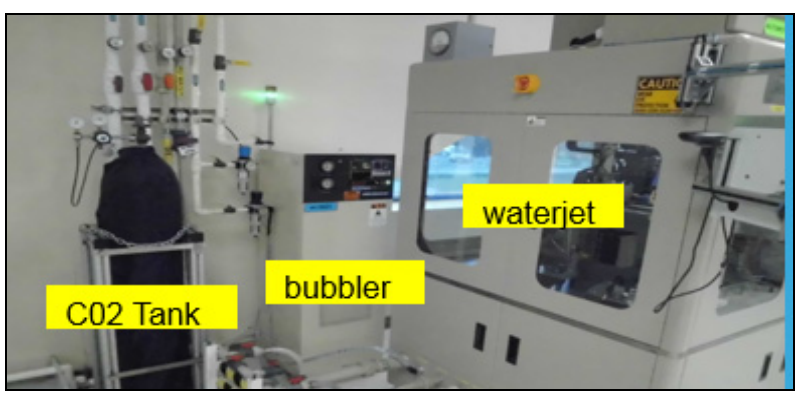

Fig. 13 Installed $\mathrm{CO}_{2}$ bubbler at waterjet deflash process.

ground. Hence more amount of charge $Q$ of the device could be discharged at a period of time $t$.

To lower the water equivalent resistivity at waterjet station, there are 2 possible options - use $\mathrm{CO} 2$ bubbler or use RO (reverse osmosis) water with $0.1 \mathrm{M} \Omega$ resistivity. Using the scoring matrix (higher score the better), the use of $\mathrm{CO}_{2}$ bubbler is found to be more cost effective and has lower risk of failure, refer to Table 3. The use of RO water is more costly as there is a need to invest on new facilities. Also, there is a risk of foreign material deposition on the device if the water is not deionized.

Pokayoke mechanism was installed so as not to allow the waterjet machine to proceed when the water resistivity is above the limit, brought by depleted $\mathrm{CO}_{2}$ tank or defective bubbler.

After optimization of the waterjet deflash process and implementation of all corrective and improvement actions, leakage current occurrence greatly reduced from a baseline of $5,784 \mathrm{ppm}$ to just $20 \mathrm{ppm}$ for workweek 1632-44, as highlighted in Fig. 15.

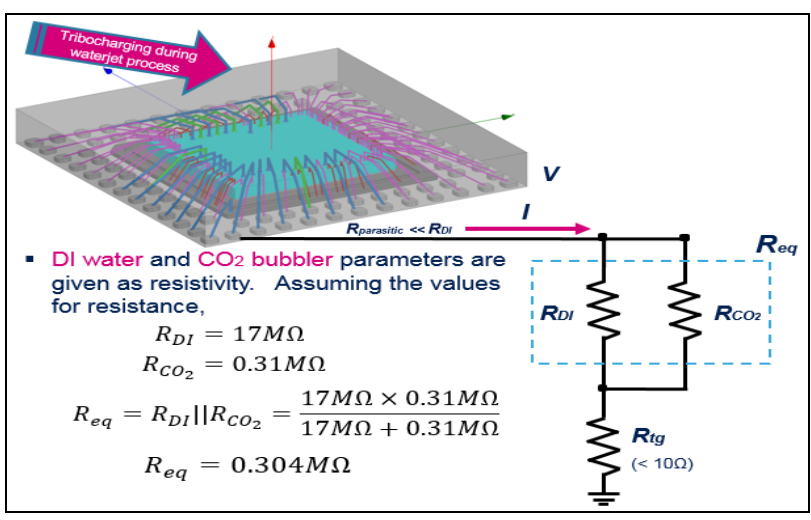

Fig. 14 ESD model, equivalent resistance of discharge path.

Table 3 Scoring matrix for lowering DI water's resistivity.

\begin{tabular}{|c|c|c|c|c|}
\hline \multirow{2}{*}{ Alternative Solution } & \multicolumn{3}{|c|}{ Selection criteria* } & \multirow{2}{*}{ Score } \\
\hline & Effectiveness & Cost & Quality & \\
\hline Use of $\mathrm{CO}_{2}$ Bubbler & 9 & 9 & 9 & 729 \\
\hline Use of RO Water & 9 & 7 & 7 & 441 \\
\hline
\end{tabular}



Leakage Current Failures on QFN-mr Leadframe Devices

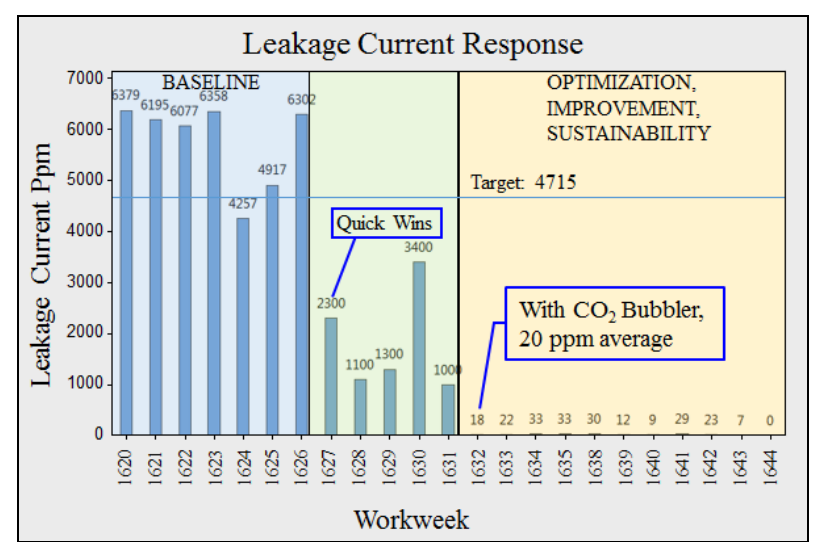

Fig. 15 Leakage current ppm improvement after optimization and implementation of all improvement and corrective actions.

Specifications such as FMEA (failure mode and effects analysis), control plan, and work instructions were updated based on the findings and the corrective and improvement actions done.

\section{Conclusion}

Leakage current failures were significantly reduced from $5,784 \mathrm{ppm}$ average to $20 \mathrm{ppm}$ for workweek 1632-44 by optimizing the waterjet deflash process by reducing the water resistivity through the use of $\mathrm{CO}_{2}$ bubbler, eliminating ESD events through grounding of floating machine parts, ensuring the allowed resistance value according to the specifications, and sustaining ESD controls. This great achievement took into account and in mind the motivation to deliver high quality products to customers given the fast-paced and demanding market.

\section{Acknowledgments}

The authors would like to extend the appreciation and credits to all members of the leakage current task force team and to the STMicroelectronics Calamba Management Team.

\section{References}

[1] ESD Association, Fundamentals of ESD, Device Sensitivity and Testing, Rome, NY, 2011.

[2] Llana, F., et al., 2016. "Practical, Cost Efficient, and Systematic Approach in Resolving Supply Current Failures during Unit Testing of QFN-mR BiCMOS Device." Presented at 26th ASEMEP Technical Symposium.

[3] Disco Engineering and R\&D Division. 2016. "Wafer ESD in Dicing Saws and the Effect of the Countermeasures." Dicer Engineering Department, Disco.

[4] Padilla, E., et al. 2015. "Plasma Optimization in Addressing Test Leakage Fails for BCD Wafer Technology." Presented at the 25th ASEMEP Technical Symposium.

[5] Mosbarger, R., and Hickey, D. J. 1994. "The Effects of Materials and Post-Mold Profiles on Plastic Encapsulated Circuits." In Proceedings of Reliability Physics Symposium, 1994, 32nd Annual Proceedings, San Jose, CA, USA.

[6] Singh, A. 2017. "Investigation and Resolution of Current Leakage Failure Caused by Carbon Black Agglomeration in Mold Compound." International Symposium on Microelectronics 2017 (1): 000685-8. 